\title{
Infrações Ambientais Constatadas Pela Polícia Ambiental no Litoral Centro-Norte de Santa Catarina
}

\author{
Camile Sothe ${ }^{1}$, Luís Cláudio Goetten ${ }^{1}$ \\ ${ }^{1}$ Polícia Militar Ambiental, Polícia Militar de Santa Catarina - PMSC, Tijucas/SC, Brasil
}

\begin{abstract}
RESUMO
Este estudo realizou o levantamento de 465 autos de infração ambiental (AIA) lavrados na área de abrangência da Polícia Militar Ambiental (PMA) de Tijucas, no período de 2010 até 2014. Para a análise, utilizou-se a estatística descritiva aliada com informações obtidas na literatura. Os resultados mostraram que as principais tipificações da área de estudo estão relacionadas à flora, sendo verificado aproximadamente 131 ha de áreas afetadas nesse período. O município com maior incidência de infrações ambientais foi Nova Trento, seguido de Camboriú. Foi verificado que as principais motivações dos autuados ao suprimir a vegetação nativa foram para terraplanagem e construção civil nos municípios mais sujeitos a expansão urbana e para realizar plantio de espécies exóticas (eucalipto) nas áreas rurais. Os resultados mostraram a necessidade de se direcionar os esforços da PMA no combate às infrações ambientais, principalmente em ações de cunho preventivo, como educação ambiental e manejo florestal sustentável.
\end{abstract}

Palavras-chave: Mata Atlântica, desmatamento, educação ambiental.

\section{Environmental Violations Identified by Environmental Police in Center-North Coast of Santa Catarina}

\begin{abstract}
This study conducted a survey of 465 notices of environmental violations (NEV) issued in the area covered by the Environmental Military Police (EMP) of Tijucas in the period of 2010 to 2014. For the analysis, we used descriptive statistics combined with information obtained in the literature. The results showed that the main typifications of the study regard the flora, with approximately 131 ha of affected areas scanned during this period. The municipality with the highest incidence of environmental violations was Nova Trento, followed by Camboriú. It has been verified that the main motivation of violators to suppress native vegetation was earthwork and construction in the municipalities more subject to urban expansion, and to execute planting of exotic species (eucalyptus) at the rural areas. The results showed the necessity to target EMP's efforts in combating environmental violations, especially in preventive actions, such as environmental education and sustainable forest management.
\end{abstract}

Keywords: Atlantic Forest, deforestation, environmental education.

\section{INTRODUÇÃO}

A crescente preocupação com a degradação ambiental no mundo e, em especial, no Brasil, culminou com a inclusão da matéria ambiental na Constituição.
Diante disto, a concepção de leis e mecanismos jurídicos de defesa do meio ambiente tornou obrigatória a atuação da polícia ostensiva na preservação do ambiente 
(Venâncio, 2013). A Constituição Federal de 1988 impôs ao Poder Público e a coletividade o dever de defender e preservar um ambiente de qualidade.

A criação de leis ambientais mais rígidas demonstra uma maior preocupação do Poder Público em proteger os recursos naturais (Borges et al., 2009). Milaré (2003) afirma que foi a partir de 1980 que a legislação brasileira começou a se preocupar com o meio ambiente de uma forma global e integrada. A Lei de Crimes Ambientais (LCA), n. 9.605/98 (Brasil, 1998) e o Decreto Federal (DF) n. 6.514/08 (Brasil, 2008) surgiram para dispor sobre as sanções penais e administrativas derivadas de condutas e atividades lesivas ao meio ambiente (Costa, 2010).

No âmbito estadual, Santa Catarina (SC) instituiu seu próprio Código do Meio Ambiente, por meio da Lei n. 14.675, de 2009 (Santa Catarina, 2009), criada para adequar a legislação nacional à realidade do estado catarinense. Essa lei, em seu artigo 10, inciso III, institui a Fundação do Meio Ambiente de SC (FATMA) e a Polícia Militar Ambiental (PMA) como órgãos integrantes do Sistema Estadual do Meio Ambiente, responsáveis pela execução, aplicação e fiscalização do cumprimento da legislação ambiental. Nesse sentido, a PMA atua de forma preventiva ou repressiva, constatando ilícitos ambientais, produzindo documentos que são encaminhados às esferas administrativa e judicial, para a devida responsabilização (Venâncio, 2013).

O Auto de Infração Ambiental (AIA) é o documento pelo qual a PMA certifica a existência de dolo à legislação e impõe penalidades ao infrator. Ele dá início ao processo administrativo para se apurar conduta lesiva ao meio ambiente. Desde 2009, todos os AIAs e respectivos processos administrativos ambientais passaram a ser cadastrados no sistema de Gestão de Acompanhamento de Infrações Ambientais (GAIA). Apesar de esse sistema fornecer os quantitativos de AIAs lavrados no estado e sua tipificação, não é possível uma visualização célere do conteúdo geral desses autos. Para isso, é necessário abrir cada processo e investigar os dados e as informações nele contidas, tarefa temporalmente custosa aos interessados. Por esse motivo, a PMA de SC ainda carece de estatísticas internas acerca dos crimes e infrações ambientais constatadas pelos agentes autuantes.

Pressupõe-se que conhecer as principais infrações ambientais cometidas contra o meio ambiente, sua localização espacial, a motivação dos autuados, a quantidade de áreas degradadas e a evolução temporal dessas tipificações contribua para o planejamento e tomada de decisões no âmbito da PMA. Essa melhor atuação poderia ocorrer tanto em ações repressivas, direcionando o foco de atuação do órgão para as chamadas "zonas quentes", ou seja, locais em que os crimes ambientais são mais frequentes, quanto nas ações preventivas, como com a elaboração de programas voltados à educação ambiental.

Nesse contexto, o objetivo deste trabalho foi explorar os AIAs lavrados na área de abrangência de uma das unidades da PMA de SC, a fim de apresentar aos órgãos de fiscalização e à sociedade um panorama da ocorrência de crimes ambientais da região. O estudo pretendeu não só apresentar o quantitativo de AIAs lavrados, mas também debater as possíveis causas associadas, especialmente em relação a flora, na expectativa de fornecer subsídios para minimizar a situação crescente de crimes e infrações ambientais na região. Com o mapeamento das ocorrências, espera-se fornecer ferramentas para o planejamento e definição de estratégias nas tomadas de decisões no campo, como prevenção, combate e fiscalização de crimes e infrações ambientais.

\section{MATERIAL E MÉTODOS}

\section{1. Área de estudo}

Á área de estudo compreende 10 municípios abrangidos pelo $3^{\circ}$ Grupo do $2^{\circ}$ Pelotão da $1^{\text {a }}$ Companhia do BPMA de SC $\left(3^{\circ} \mathrm{Gp} / 2^{\circ} \mathrm{Pel} / 1^{\mathrm{a}} \mathrm{Cia} / \mathrm{BPMA}\right)$. Os municípios estão inseridos no Bioma Mata Atlântica e pertencem à região fitoecológica de Floresta Ombrófila Densa (Klein, 1978). Quanto à divisão política, os municípios estão situados em duas mesorregiões de SC: Vale do Itajaí (Balneário Camboriú, Camboriú, Itapema, Porto Belo e Bombinhas) e Grande Florianópolis (Canelinha, Major Gercino, Nova Trento, Porto Belo, São João Batista e Tijucas). Em agosto de 2013, essa unidade passou a atender mais quatro municípios: Itajaí, Navegantes, Balneário Piçarras e Penha, os quais não foram contabilizados neste estudo.

\subsection{Análise dos dados}

Os dados foram coletados do GAIA, sistema desenvolvido pela FATMA, no qual se obtiveram as seguintes informações de cada Processo Administrativo 
Ambiental: número do AIA; município da infração ambiental; tipo criminal (flora, fauna etc.); enquadramento da infração conforme DF n. 6.514/08; coordenadas geodésicas do local da infração; personalidade do infrator (física ou jurídica); tamanho da área afetada; apreensões realizadas; motivação dos infratores ao realizar a conduta; e estádio sucessional da vegetação destruída.

Os dados da planilha foram dispostos no aplicativo Excel e analisados com estatísticas descritivas (Sokal \& Rohlf, 1995), por meio de gráficos. Usou-se o método de Análise de Conteúdo (Franco, 2005), em que o referencial teórico pesquisado foi relacionado com a visão do pesquisador.

Para análise espacial dos dados, a planilha do Excel foi importada no Sistema de Informação Geográfica QGIS 2.8.2. Com o campo relativo às coordenadas geodésicas foi possível plotar o local de cada infração no QGIS. Para a visualização dos principais locais de ocorrência de crimes e infrações ambientais, as denominadas "zonas quentes", foram elaborados mapas de densidade do tipo cluster (agrupamento). A análise de cluster depende da proximidade dos pontos que representam os incidentes. Em geral, o programa primeiramente estabelece um ponto de partida arbitrário, definido como "semente". O sistema encontra o dado estatisticamente mais afastado da semente e faz dele a segunda semente, dividindo os dados em dois grupos. São então calculadas as distâncias a partir de cada semente até outros pontos e os clusters baseados na nova semente são desenvolvidos, de modo que as somas das distâncias dentro do cluster sejam minimizadas. Atribuiu-se um raio de $20 \mathrm{~km}$ para elaboração dos clusters, ou seja, foram agregados os pontos que estivessem na proximidade de até $20 \mathrm{~km}$ do ponto central do cluster.

\section{RESULTADOS E DISCUSSÃO}

\subsection{Panorama geral das principais tipificações constatadas}

Durante o período estudado, foram lavrados 465 AIAs, englobando nove diferentes categorias de infrações ambientais de acordo com o DF 6.514/08. Predominaram crimes e infrações relacionados à flora, com destaque para os artigos 43 , 48 e 50 descritos no
DF 6.514/08. Nesse período ocorreram apreensões de 328 st de lenha ou madeira nativa, além de 615 toras de espécies florestais nativas, essas relacionadas aos AIAs enquadrados no artigo 47 do DF 6.514/08 (Brasil, 2008).

Das 63 autuações enquadradas no artigo 24, relacionado à fauna, verificou-se que 58 envolveram apreensões de aves silvestres, as quais eram mantidas irregularmente em cativeiro. No período estudado, 620 aves silvestres foram apreendidas e encaminhadas ao setor de reabilitação. O número elevado de aves silvestres em cativeiro pode ser em função do forte apelo cultural da região, adepta dessa prática. Os infratores alegaram manter as aves em cativeiro apenas por gostarem de seu canto. Alguns ainda fazem a captura para comercializar as aves. Apenas cinco AIAs enquadrados no artigo 24 corresponderam a infração de crime de caça de animais silvestres, o que, em parte, está relacionado com a dificuldade de se flagrar esse crime. Geralmente, parte-se de uma denúncia e, diferentemente de outras ocorrências, como supressão de vegetação, por exemplo, na caça há a necessidade de o infrator ser flagrado durante a conduta criminosa, ou em posse da caça abatida, para que então possa ser lavrado o AIA.

Quanto à personalidade dos infratores, foi constatado que $20 \%$ das infrações foram cometidas por personalidade jurídica e as demais, por pessoas físicas. A personalidade jurídica prevaleceu apenas nos crimes de mineração (art. 63 do DF 6.514/08) e poluição (art. 62 e 66 do DF 6.514/08) (Brasil, 2008). Tais infrações estão relacionadas à inexistência de licença ambiental para funcionamento de atividades potencialmente poluidoras, como extração de recursos minerais. Foi verificado que algumas empresas autuadas possuíam licença para a atividade, porém deixaram de atender as condicionantes delas, fato igualmente impactante ao meio ambiente.

A Figura 1 mostra a evolução anual do número de AIAs lavrados no período de estudo. Apesar de haver um pico pronunciado de AIAs lavrados no ano de 2013, com redução em 2014, é possível perceber uma tendência crescente no número de autuações, demonstrada pela reta. Em 2013 houve uma situação atípica no $3^{\circ} \mathrm{Gp} / 2^{\circ} \mathrm{Pel} / 1^{\mathrm{a}} \mathrm{Cia} / \mathrm{BPMA}$, o que contribuiu para essa elevação no número de AIA. Em atendimento a uma requisição do Ministério Público Estadual que versava sobre invasão de área de preservação permanente 
(APP) no município de Porto Belo, foram lavrados 23 AIAs em um único dia. A tendência crescente do número de AIA lavrados é preocupante, pois pode ser um indicativo de que os crimes ambientais vêm aumentando na região estudada.

A Figura 2 mostra os AIAs lavrados conforme o município. Camboriú e Nova Trento foram os municípios com maior número de AIAs, seguidos de São João Batista e Tijucas. Percebe-se novamente que, no ano de 2013, houve maior número de AIAs lavrados, principalmente em Camboriú e Nova Trento. Pode-se inferir que os municípios de maior incidência de infrações ambientais são os que possuem área rural mais expressiva em relação à urbana, o que

AIA

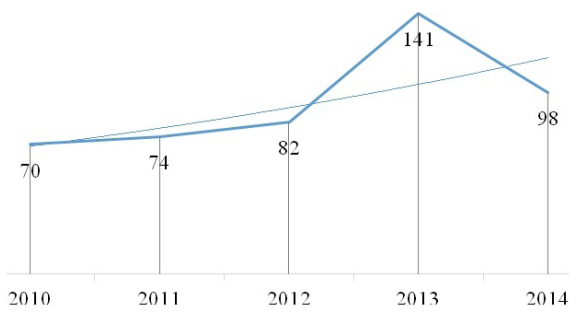

Figura 1. Número de AIA lavrados anualmente no período $2010 / 2014$ pelo $3^{\circ} \mathrm{Gp} / 2^{\circ} \mathrm{Pel} / 1^{\mathrm{a}} \mathrm{Cia} / \mathrm{BPMA}$.

Figure 1. Numbers of NEVs issued annually in the period $2010 / 2014$ by $3^{\circ} \mathrm{Gp} / 2^{\circ} \mathrm{Pel} / 1^{\mathrm{a}} \mathrm{Cia} / \mathrm{BPMA}$. propicia maior ocorrência dos crimes e infrações relacionados à flora. Além disso, a atuação da PMA predomina em zonas rurais, já que áreas urbanas são, em parte, controladas pelas fundações municipais de meio ambiente. Isso significa que nos municípios que possuem fundações do meio ambiente, que é o caso de Porto Belo, Itapema, Bombinhas, Balneário Camboriú e Camboriú, podem ter sido lavrados AIAs nas áreas urbanas durante esse período, porém não contabilizados nesse levantamento, que limitou-se aos autos lavrados pela PMA.

O mapa de cluster (Figura 3) mostra os focos das infrações ambientais constatadas no período estudado. Como relatado anteriormente, percebe-se que o maior número de ocorrências concentradas (em vermelho) está nos municípios de Camboriú, Nova Trento e São João Batista. Um dos focos de ocorrências no município de Porto Belo refere-se ao atendimento da requisição do Ministério Público Estadual no ano de 2013.

\subsection{Principais crimes e infrações ambientais contra a flora}

Verificou-se que 131,2 ha de área foram afetados no período de cinco anos por destruição de vegetação ou por atividade de mineração. Esse valor corresponde a 19\% do detectado para um período de dois anos para o estado de SC pela Fundação SOS Mata Atlântica \& INPE (2015). Porém deve-se pontuar que os

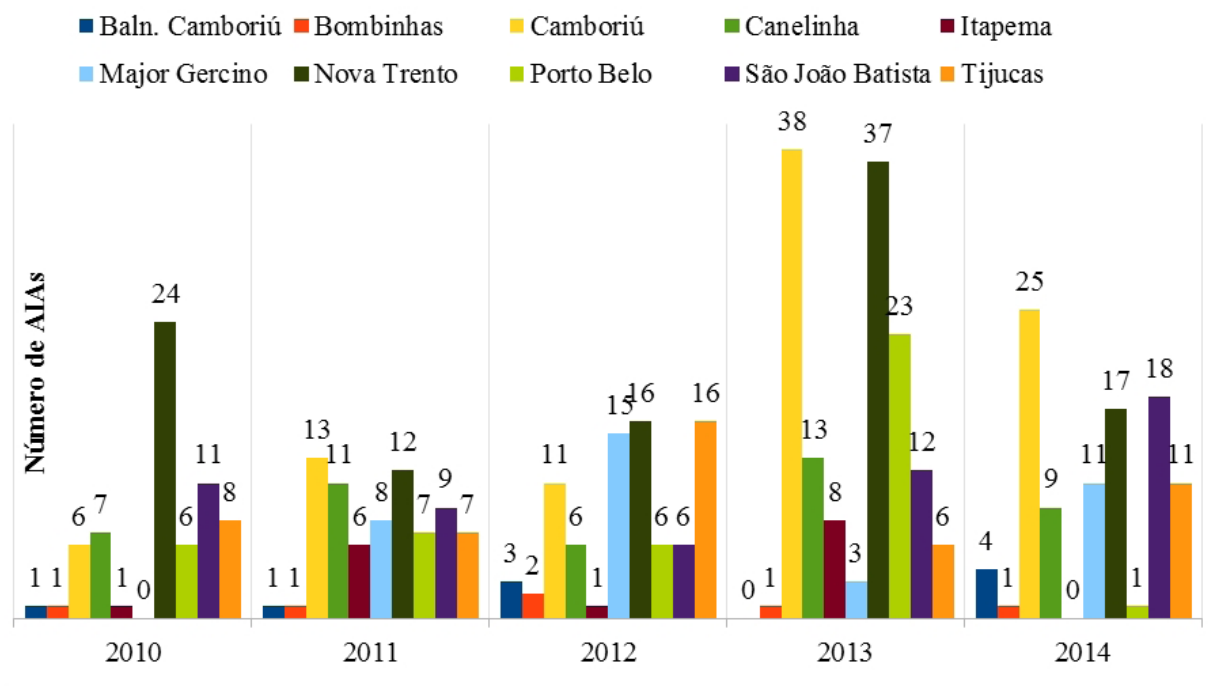

Figura 2. Número de AIA lavrados anualmente nas cidades pertencentes à área de atuação do $3^{\circ} \mathrm{Gp} / 2^{\circ} \mathrm{Pel} / 1^{\mathrm{a}} \mathrm{Cia} / \mathrm{BPMA}$. Figure 2. Numbers of NEVs issued annually in the cities belonging to $3^{\circ} \mathrm{Gp} / 2^{\circ} \mathrm{Pel} / 1^{\mathrm{a}} \mathrm{Cia} / \mathrm{BPMA}$. 


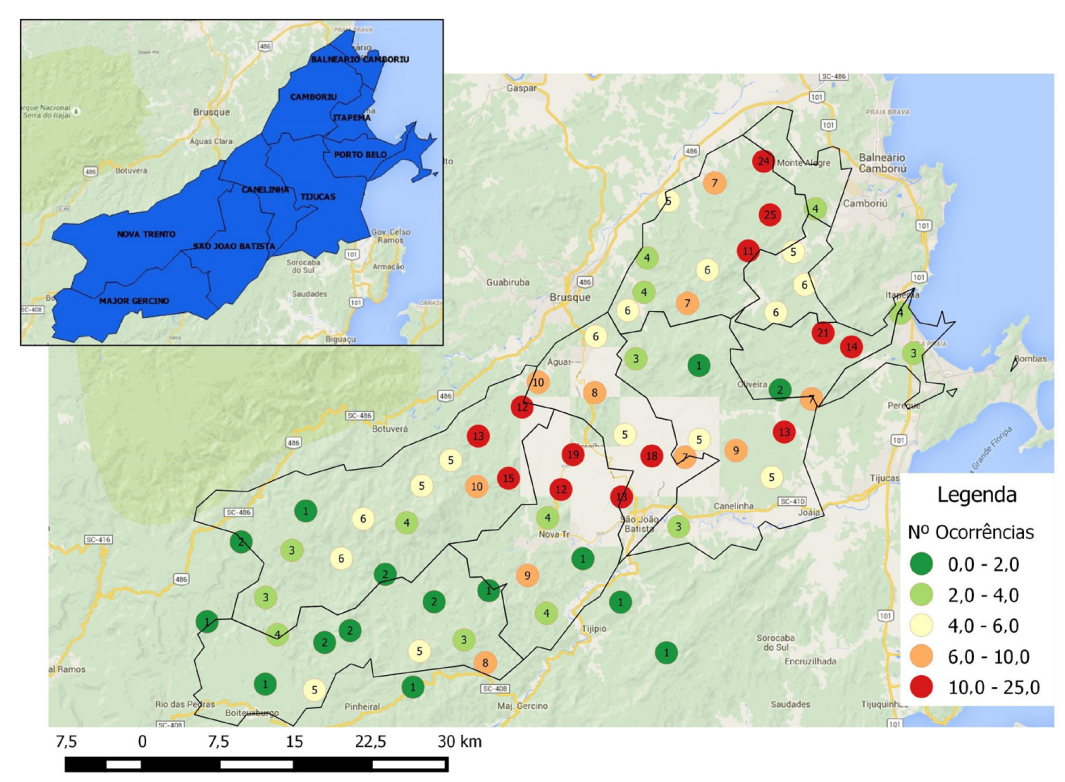

Figura 3. Mapa de cluster com a distribuição das ocorrências ambientais no período 2010 a 2014.

Figure 3. Cluster map with the distribution of the environmental occurrences in the period 2010 to 2014.

levantamentos pela Fundação SOS Mata Atlântica e INPE não consideraram o desmatamento dos estádios iniciais de regeneração, os quais também necessitam autorização, subestimando o real valor de áreas desmatadas no estado. Além disso, a supressão de vegetação só foi contabilizada quando a área afetada foi superior a três hectares, o que não retrata muitas das ocorrências na região de estudo, que possui mais intervenções pontuais provenientes da construção civil, terraplanagem e pequenas áreas agrícolas.

No período estudado verificou-se que foram suprimidas 107,87 ha de vegetação nativa, correspondentes aos AIAs enquadrados nos artigos 43 , 48 e 50 do DF 6.514/08 (Brasil, 2008). Desse total, foram destruídos 34,5 ha de APPs, totalizando, aproximadamente, um terço do que foi desmatado na área de estudo (32\%). Sabe-se, no entanto, que tais números podem não revelar a verdadeira extensão de área desmatada na região, sendo apenas o que foi constatado pelos agentes autuantes e que resultaram na lavratura do AIA. O pouco efetivo de policiais ambientais, aliado a grande área de atuação do $3^{\circ} \mathrm{Gp} / 2^{\circ} \mathrm{Pel} / 1^{\mathrm{a}} \mathrm{Cia} / \mathrm{BPMA}$, que, se somados os 10 municípios, corresponde a $1.772,16 \mathrm{~km}^{2}$, torna infactível a tarefa de fiscalizar e constatar todos os crimes e infrações cometidos.
Outros 23 ha foram atingidos por atividades de mineração (art. 63 do DF 6.514/08, Brasil, 2008) de forma irregular, ou seja, sem projeto e licença da autoridade competente. A atividade de mineração vem sendo bastante explorada no Brasil, principalmente por médias e pequenas empresas (Farias et al., 2014). Porém os empreendimentos que não atendem aos requisitos legais no que diz respeito às normas ambientais, como realização de Estudo de Impacto Ambiental, acabam por gerar danos maiores ao meio ambiente, já que carecem de um projeto para minimizá-los e controlá-los. Dentre os impactos da mineração destacam-se o assoreamento de rios e corpos d'água em virtude do carreamento de materiais, erosão de extensas áreas de extração. Essa exploração não gera impactos apenas aos corpos hídricos e ao solo, mas também impacto visual, do ar e sonoro, em alguns casos.

A Figura 4 mostra a frequência das principais tipificações relacionadas à flora e mineração conforme o município. Visualiza-se que o município de Camboriú teve a maior extensão de área degradada conforme os artigos 48 e 50 . Nessas duas tipificações, foram mensurados aproximadamente 25 ha de área destruída. Além das atividades de supressão de vegetação, Camboriú também teve a maior área atingida por atividades 


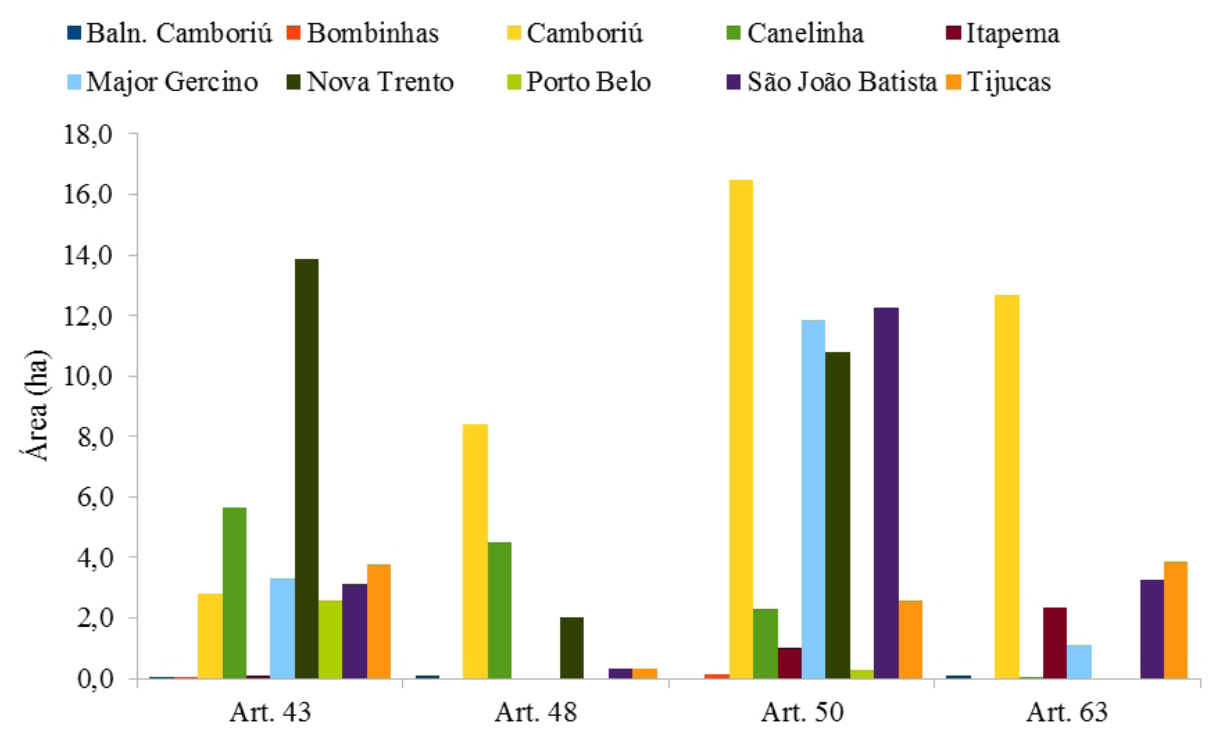

Figura 4. Áreas degradadas constatadas resultantes de infrações ambientais conforme $\mathrm{DF}^{\circ}$ 6.514/08 no período estudado.

Figure 4. Degraded areas resulted from identified environmental violations as DF $\mathrm{n}^{\circ} 6,514 / 08$ in the period studied.

de mineração (art. 63 do DF 6.514/08, Brasil, 2008), mensurados quase 13 ha.

A ampliação dos perímetros urbanos em municípios litorâneos, como Camboriú, é um dos principais motivos para a substituição de áreas anteriormente ocupadas por vegetação nativa por áreas de uso comercial e imobiliário. Nesse caso, além do aumento do valor da terra, a supressão da vegetação de forma clandestina potencializa a sua substituição. O município de Camboriú, apesar de não ser um balneário, está integrado a Balneário Camboriú, que possui a maior densidade demográfica $\left(2.337,7 \mathrm{hab} / \mathrm{km}^{2}\right)$ do estado de SC (IBGE, 2014). Segundo Bastos (2007), dentre os elementos que podem ser elencados como responsáveis pela expansão urbana e demográfica dos municípios do Vale do Itajaí, está a soma dos fatores de atração (geração de empregos pela indústria nos grandes centros urbanos) e de repulsão (impossibilidade de o trabalhador rural tornar-se pequeno proprietário). Sabe-se ainda que as pessoas de menor renda, por não terem condições financeiras de adquirir imóveis em Balneário Camboriú, migram para a cidade próxima, no caso, Camboriú, o que tem propiciado a supressão clandestina em áreas com vegetação nativa e expansão urbana desordenada (Bastos, 2007).
Os municípios de São João Batista e Major Gercino tiveram maiores áreas degradadas pela atividade de supressão de vegetação fora de APP (art. 50 do DF 6.514/08). Já o município de Nova Trento foi o que teve maior extensão de APPs destruídas (art. 43 do DF 6.514/08), somando quase 14 ha, o que pode ser associado ao fato de esse município ser rico em cursos d'água, possuindo, portanto, maiores áreas consideradas APP de margem de curso d'água. Diferentemente de Camboriú, esses três municípios não estão englobados pelo processo de expansão urbana. Dessa forma, infere-se que os próprios produtores rurais da região exercem pressão para a conversão das áreas de vegetação nativa para outros usos da terra.

Siminski \& Fantini (2007) elencaram algumas razões para o distanciamento e desinteresse dos agricultores em utilizar, de forma sustentável, os remanescentes florestais de suas propriedades, dentre elas: legislações restritivas ao uso dos recursos florestais nativos, a falta de alternativas ecologicamente aceitas e o não reconhecimento dos serviços ambientais proporcionados pelos agricultores familiares por intermédio de suas florestas. Em um questionário aplicado às famílias que moram próximas às áreas florestais, durante a realização do Inventário Florístico Florestal de Santa Catarina em 2010, foi verificado que a expressão 
"manejo florestal" se revelou desconhecida por cerca de um terço dos entrevistados. Além disso, segundo esse questionário, ao indicar atitudes para proteção das florestas, a maioria dos entrevistados pensa que isso só é possível se deixarem a floresta intocável, o que demonstra a falta de conhecimento acerca das possibilidades de manejo sustentável desses recursos (Justen et al., 2012).

A Figura 5 mostra as principais motivações alegadas pelos autuados ao destruírem a vegetação nativa. Percebe-se que a principal motivação é a construção de benfeitorias, incluindo-se os aterros e terraplanagens, que podem estar relacionados a essa finalidade. Visualiza-se também que essa motivação predomina nas infrações ambientais enquadradas no art. 43 do DF 6.514/08, atingindo APP. Atividades como construção e terraplanagem próximas aos corpos hídricos podem ocasionar a contaminação das águas, seja com o despejo de dejetos oriundos das construções, seja com o assoreamento e erosão. Tais atividades podem impedir de forma permanente a regeneração natural da paisagem.

Outro motivo alegado pelos infratores para justificar a destruição de vegetação nativa foi para realizar o plantio de espécies exóticas, como o eucalipto. Tal fato é preocupante, pois substituição de espécies nativas em prol de espécies exóticas pode ocasionar efeitos ambientais diversos, entre eles diminuição da fauna e da entomofauna local, com prejuízos ambientais irreparáveis. A monocultura, seja de eucalipto ou de qualquer outra espécie, é reconhecidamente menos capaz de suportar uma alta diversidade de fauna, devido à indisponibilidade de nichos apropriados (Silva, 2003).

Segundo a ABRAF (2013), no Brasil o gênero Eucalyptus sp. ocupa 5.102 .030 ha, correspondendo a $71 \%$ das florestas plantadas. Em SC, esse gênero ocupa 106.588 ha, o que pode justificar a forte pressão antrópica para conversão da cobertura da terra de espécies nativas para exóticas.

Dados do IBGE (2014) denotam que o município de Nova Trento produziu $63 \mathrm{mil} \mathrm{m}^{3}$ de madeira e lenha de eucalipto no ano de 2013, arrecadando $2.350 \mathrm{mil}$ reais. Seria necessário, em média, 1.400 ha de área plantada com essa espécie exótica para se atingir tais números, o que pode justificar o número expressivo de AIAs lavrados nesse município. Tijucas é o município que mais produziu madeira e lenha de eucalipto no ano de 2013, totalizando $400 \mathrm{mil} \mathrm{m}^{3}$ e gerando 22.400 mil reais com essa atividade. São João Batista produziu $80.500 \mathrm{~m}^{3}$, gerando 2.760 mil reais. Já o município de Camboriú produziu apenas $6.660 \mathrm{~m}^{3} \mathrm{de}$ madeira de eucalipto, arrecadando 276 mil reais. Esses dados podem justificar a forte pressão antrópica sobre a conversão do uso da terra para culturas exóticas.

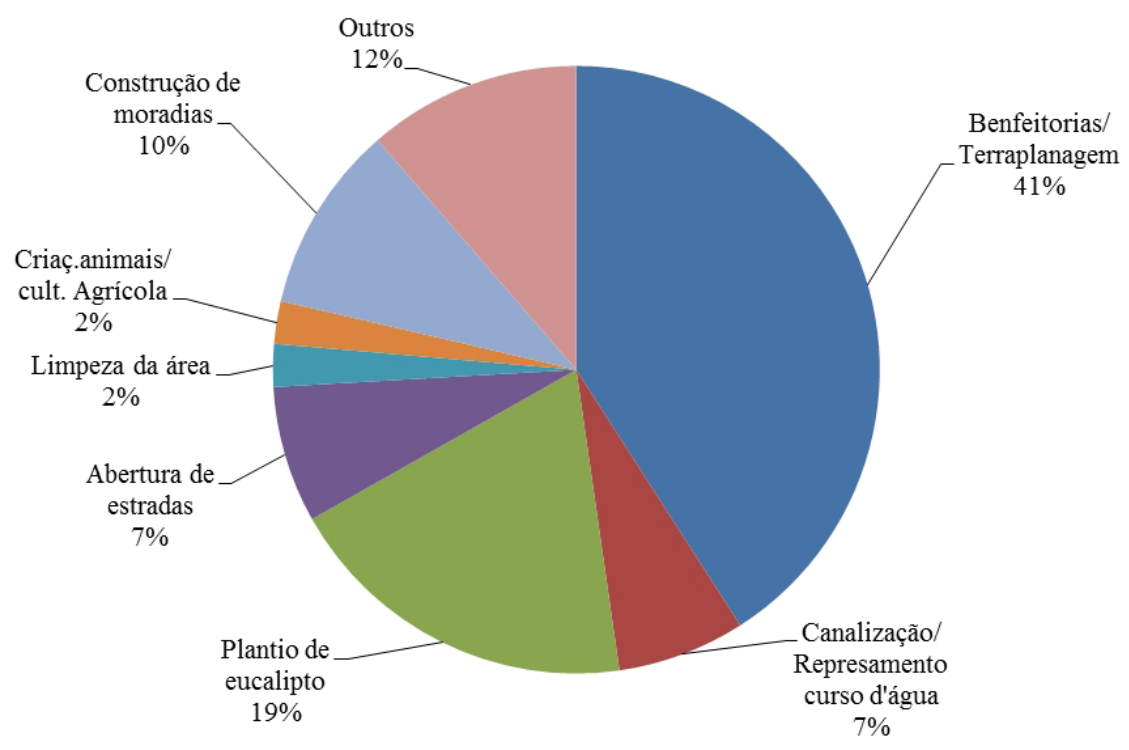

Figura 5. Motivações alegadas pelos autuados em crimes contra a flora constatados pela PMA.

Figure 5. Motivations alleged by violators in crimes against flora founds by the EMP. 
No caso de Camboriú, a produção madeireira mais baixa pode estar corroborando a hipótese de que a ação antrópica sobre o desflorestamento pode realmente estar relacionada a conversão das áreas em loteamentos (pressão imobiliária).

Siminski \& Fantini (2010), ao realizarem o levantamento de pedidos de supressão de vegetação para a FATMA, constataram que, na área rural, a implantação de reflorestamentos com espécies exóticas destacou-se como a principal opção’ de uso da terra após a supressão da vegetação. Segundo os autores, o reflorestamento com exóticas foi responsável por $65 \%$ do número de pedidos de supressão na zona rural. Esses dados corroboram os do presente estudo, com a diferença de que, nesse caso, os infratores não chegaram a procurar os órgãos responsáveis para obter autorização para supressão da vegetação. Ainda segundo Siminski \& Fantini (2010), a opção pelos reflorestamentos com espécies exóticas pode ser apenas reflexo do contexto florestal atual, em que os rendimentos econômicos e políticas florestais estimulam essa conversão.

Os AIAs enquadrados no artigo 50 descrevem o estádio sucessional da vegetação destruída (Figura 6). Percebe-se que na maior parte desses AIAs, a vegetação destruída foi caracterizada como em estádio médio de regeneração, seguida do inicial.

A supressão da vegetação no estádio médio de regeneração está relacionada à atividade agropecuária $\mathrm{e}$ de reflorestamento nas áreas rurais. Cabe ainda destacar que não é permitido o corte de Floresta Ombrófila Densa (FOD) em estádio médio sem autorização, conforme Lei Federal n. 11.428/2006 (Brasil, 2006). Trata-se de vegetação que já possui porte considerável,

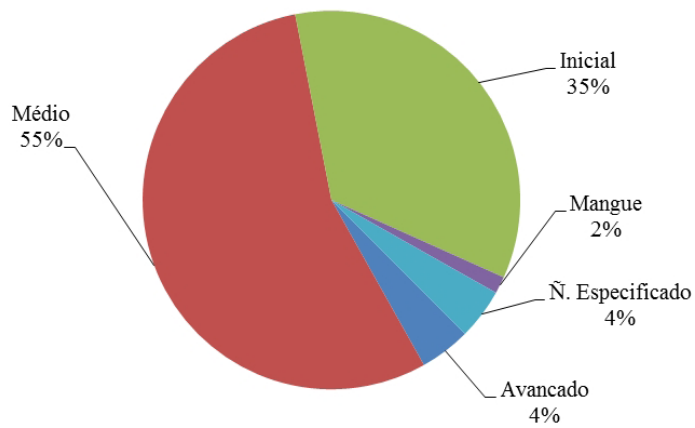

Figura 6. Estádio sucessional da vegetação destruída conforme o artigo 50 do DF n ${ }^{\circ} 6.514 / 08$.

Figure 6. Successional stage of deforested vegetation according to article 50 as DF $n^{\circ} 6,514 / 08$. além de certa complexidade e número de espécies. Ao destruí-la, mesmo que o motivo da degradação cesse, em geral, ela demora mais de 10 anos para retornar ao estádio anterior aos danos.

Trauczynski (2013), ao realizar o levantamento de perícias criminais relativos à flora no estado de SC, constatou que a maior parte desses laudos em área de FOD era de danos em vegetação nos estádios inicial ou médio. De acordo com o autor, o estádio avançado encontra fortes restrições na legislação federal sobre o tema (Brasil, 2006), o que diminui a pressão sobre esse estádio de regeneração.

Siminski \& Fantini (2004), ao estudarem o sistema de agricultura de "pousio" ou "roça de toco", tradicional na região de São Pedro de Alcântara, alertam para reclamações dos agricultores familiares de que não há possibilidade de regeneração do solo para novos plantios de cultura antes que a vegetação alcance o estádio médio. Dessa forma, há forte pressão para derrubada desse estádio em áreas rurais das regiões em que se aplica a prática de pousio.

Destaca-se que os remanescentes de vegetação nativa, além de oferecerem ampla gama de possibilidades econômicas, são fundamentais para manter a produtividade em sistemas agropecuários. Exercem influência direta na conservação da água, na manutenção da biodiversidade, na qualidade do solo, na melhoria da produção, além de na manutenção de abrigo para agentes polinizadores, dispersores de sementes e inimigos naturais de pragas, dentre outras (Bastos \& Silva, 2014). Necessita-se, portanto, realizar conscientização da população quanto a essa importância, para além de o poder público ter um papel mais expressivo no incentivo da proteção ambiental, esclarecendo e incentivando o uso sustentável dos recursos florestais. Esse estímulo poderia se dar pelo pagamento por serviços ambientais produzidos pelos ecossistemas, ou, principalmente, pelo incentivo ao manejo econômico das formações secundárias, a exemplo do que propõem Siminski \& Fantini (2007).

\section{CONCLUSÕES}

O panorama geral dos crimes e infrações ambientais no período de cinco anos mostrou uma situação preocupante, principalmente quanto aos crimes contra a flora. A expansão urbana desordenada e a pressão para a conversão de áreas de floresta nativa para exóticas 
foram apontados como os principais motivadores da destruição da vegetação nativa na região de estudo.

Outros crimes e infrações ambientais, como os relacionados à extração mineral irregular e poluição, apesar de terem menor número de AIAs lavrados na região de estudo, não devem ser ignorados, já que tais impactos algumas vezes são irreversíveis, diferentemente do desmatamento, por exemplo. Quanto aos crimes relacionados à fauna, a captura e manutenção de aves silvestres em cativeiro infelizmente representa a realidade da região, culturalmente adepta dessa prática. Os pássaros silvestres desempenham papel fundamental no meio ambiente, como integrantes da cadeia alimentar, dispersores de sementes e embelezadores da natureza.

Nota-se que a abordagem da fiscalização e da punição tem se mostrado pouco efetiva. Mesmo com os órgãos ambientais impondo valores altos de multa aos infratores ambientais, muitos ainda preferem arriscar-se e atuar na clandestinidade. Acredita-se que investir em ações de cunho preventivo, como programas e parcerias com instituições de ensino e de pesquisa, buscando divulgar e implantar práticas alternativas de manejo e uso dos recursos naturais nas propriedades, possa ter maior eficácia no combate aos crimes e infrações ambientais.

Compatibilizar o desenvolvimento econômico com a preservação do meio ambiente é ainda um grande desafio para a sociedade contemporânea. É preciso coexistência harmônica entre a atuação estatal, prestação de serviço público, meio ambiente e exploração de atividade econômica para que os recursos atualmente colocados à disposição do homem não se esgotem no futuro. O Estado, no exercício de suas atividades, não pode agir alheio a esse fato.

\section{STATUS DA SUBMISSÃO}

Recebido: 4 abr., 2016

Aceito: 10 nov., 2016

\section{AUTOR(ES) PARA CORRESPONDÊNCIA}

\section{Camile Sothe}

Polícia Militar Ambiental, Polícia Militar de Santa Catarina - PMSC, Rua Coronel Conceição, 870, CEP 88200-000, Tijucas, SC, Brasil e-mail: camilesothe@yahoo.com.br

\section{REFERÊNCIAS}

Associação Brasileira de Produtores de Florestas Plantadas - ABRAF. Anuário estatístico da ABRAF 2013 ano base 2012. Brasília, DF; 2013. 146 p.

Bastos EK, Silva RA. Perícias de danos ambientais na vegetação natural. In: Tocchetto D, organizador. Perícia ambiental criminal. 3. ed. Campinas: Millenium; 2014.

Bastos JM. Considerações sobre a urbanização do litoral catarinense. In: Anais do $10^{\circ}$ Simpósio de Geografia Urbana; 2007, Florianópolis. Florianópolis: SIMPURB; 2007.p. 1-8.

Borges LAC, Resende JLP, Pereira JAA. Evolução da legislação ambiental no Brasil. Revista em Agronegócios e Meio Ambiente 2009; 2(3): 447-466.

Brasil. Lei no 9.605, de 12 de fevereiro de 1998. Diário Oficial da República Federativa do Brasil, Brasília, DF, (1998 fev.).

Brasil. Lei no 11.428, de 22 de dezembro de 2006. Diário Oficial da República Federativa do Brasil, Brasília, DF, (2006 dez.). Seção 1, 1 p.

Brasil. Decreto Federal no 6.514, de 22 de julho de 2008. Diário Oficial da República Federativa do Brasil, Brasília, DF, (2008 jul.).

Costa EP. Poder de polícia ambiental e a administração pública. Revista Brasileira de Direito Constitucional 2010; 16: 13-24.

Farias A, Heckert BT, Kerber FF, Vieira JP, Oliveira RS. Crimes de poluição. In: Tochetto D, organizador. Perícia Ambiental Criminal. 3. ed. Campinas: Millenium; 2014.

Franco MLPB. Análise do conteúdo. 2. ed. Brasília: Liber Livros; 2005.

Fundação SOS Mata Atlântica, Instituto Nacional de Pesquisas Espaciais - INPE. Atlas dos remanescentes florestais da Mata Atlântica: período 2013-2014: relatório técnico. São Paulo: SOS Mata Atlântica; São José dos Campos: INPE; 2015.

Instituto Brasileiro de Geografia e Estatística - IBGE. Informações sobre as cidades do Brasil. Rio de Janeiro; 2014 [citado em 2015 abr 12]. Disponível em: http:// www.cidades.ibge.gov.br/

Justen JGK, Muller JJV, Toresan L. Levantamento socioambiental. In: Vibrans AC, Sevegnani L, Gasper $\mathrm{AL}$, Lingner DV, editores. Inventário florístico florestal de Santa Catarina. Blumenau: Edifurb; 2012.

Klein RM. Mapa fitogeográfico do estado de Santa Catarina. In: Reitz R, editor. Flora ilustrada catarinense. Itajaí: Herbário Barbosa Rodrigues; 1978.

Milaré E. Direito do ambiente. 3. ed. São Paulo: Editora Revista dos Tribunais; 2003.

Santa Catarina. Governo do Estado. Lei Estadual $n^{\circ}$ 14.675 de 13 de abril de 2009. Diário Oficial do Estado, Florianópolis, SC (2009 abr.). 
Silva JC. Eucalipto: desfazendo mitos e preconceitos. Revista da Madeira 2003; 69: 44-48.

Siminski A, Fantini AC. Classificação da Mata Atlântica do litoral catarinense em estádios sucessionais: ajustando a lei ao ecossistema. Floresta e Ambiente 2004; 11(2): 20-25.

Siminski A, Fantini AC. Roça-de-toco: uso de recursos florestais e dinâmica da paisagem rural no litoral de Santa Catarina. Ciência Rural 2007; 37(3): 690-696. http://dx.doi. org/10.1590/S0103-84782007000300014.

Siminski A, Fantini AC. A Mata Atlântica cede lugar a outros usos da terra em Santa Catarina. Biotemas 2010;2(23): 51-59.
Sokal RR, Rohlf FJ. Biometry: the principles and practice of statistics in biological research. 3rd ed. New York: W. H. Freeman and Co.; 1995

Trauczynski RA. Perícias criminais em delitos contra a flora no Estado de Santa Catarina: diagnóstico, metodologia e perspectivas [dissertação]. Florianópolis: Universidade Federal de Santa Catarina; 2013.

Venâncio VR. A ordem pública ambiental na sociedade de risco: a atuação da polícia ostensiva em Santa Catarina [dissertação]. Florianópolis: Universidade Federal de Santa Catarina; 2013. 